\title{
EGFR mutated non-small cell lung cancer patients: More prone to development of bone and brain metastases?
}

Citation for published version (APA):

Hendriks, L. E. L., Smit, E. F., Vosse, B. A. H., Mellema, W. W., Heideman, D. A. M., Bootsma, G. P., Westenend, M., Pitz, C., de Vries, G. J., Houben, R., Grunberg, K., Bendek, M., Speel, E-J. M., \& Dingemans, A-M. C. (2014). EGFR mutated non-small cell lung cancer patients: More prone to development of bone and brain metastases? Lung Cancer, 84(1), 86-91.

https://doi.org/10.1016/j.lungcan.2014.01.006

Document status and date:

Published: 01/04/2014

DOI:

10.1016/j.lungcan.2014.01.006

Document Version:

Publisher's PDF, also known as Version of record

\section{Document license:}

Taverne

Please check the document version of this publication:

- A submitted manuscript is the version of the article upon submission and before peer-review. There can be important differences between the submitted version and the official published version of record.

People interested in the research are advised to contact the author for the final version of the publication, or visit the DOI to the publisher's website.

- The final author version and the galley proof are versions of the publication after peer review.

- The final published version features the final layout of the paper including the volume, issue and page numbers.

Link to publication

\footnotetext{
General rights rights.

- You may freely distribute the URL identifying the publication in the public portal. please follow below link for the End User Agreement:

www.umlib.nl/taverne-license

Take down policy

If you believe that this document breaches copyright please contact us at:

repository@maastrichtuniversity.nl

providing details and we will investigate your claim.
}

Copyright and moral rights for the publications made accessible in the public portal are retained by the authors and/or other copyright owners and it is a condition of accessing publications that users recognise and abide by the legal requirements associated with these

- Users may download and print one copy of any publication from the public portal for the purpose of private study or research.

- You may not further distribute the material or use it for any profit-making activity or commercial gain

If the publication is distributed under the terms of Article $25 \mathrm{fa}$ of the Dutch Copyright Act, indicated by the "Taverne" license above, 


\title{
EGFR mutated non-small cell lung cancer patients: More prone to development of bone and brain metastases?
}

\author{
L.E.L. Hendriks ${ }^{\text {a, }}$, E.F. Smit ${ }^{b}$, B.A.H. Vosse ${ }^{a}$, W.W. Mellema ${ }^{b}$, D.A.M. Heideman ${ }^{c}$, \\ G.P. Bootsma ${ }^{\mathrm{d}}$, M. Westenend ${ }^{\mathrm{e}}$, C. Pitz ${ }^{\mathrm{f}}$, G.J. de Vries $^{\mathrm{g}}{ }^{\text {, R. Houben }}{ }^{\mathrm{h}}$, K. Grünberg ${ }^{\mathrm{c}}$, \\ M. Bendek ${ }^{i}$, E.-J.M. Speel ${ }^{i}$, A.-M.C. Dingemans ${ }^{a}$
}

\footnotetext{
a Department of Pulmonary Diseases, Maastricht University Medical Center+, PO Box 5800, 6202 AZ Maastricht, The Netherlands

b Department of Pulmonary Diseases, VU University Medical Center, PO Box 7057, 1007 MB Amsterdam, The Netherlands

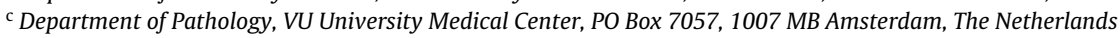

d Department of Pulmonary Diseases, Atrium Medical Center, H. Dunantstraat 5, 6419 PC Heerlen, The Netherlands

e Department of Pulmonary Diseases, VieCuri, Tegelseweg 210, 5912 BL Venlo, The Netherlands

${ }^{\mathrm{f}}$ Department of Pulmonary Diseases, Laurentius Hospital, Mgr. Driessenstraat 6, 6043 CV Roermond, The Netherlands

${ }^{g}$ Department of Pulmonary Diseases, Orbis Medical Center, PO Box 5500, 6130 MB Sittard, The Netherlands

h Department of Radiation Oncology (MAASTRO), GROW School for Oncology and Developmental Biology, Maastricht University Medical Center+,

PO Box 3035, 6202 NA Maastricht, The Netherlands

i Department of Pathology, GROW School for Oncology and Developmental Biology, Maastricht University Medical Center+, PO Box 5800, 6202 AZ Maastricht, The Netherlands
}

\section{A R T I C L E I N F O}

\section{Article history:}

Received 15 November 2013

Accepted 12 January 2014

\section{Keywords:}

NSCLC

EGFR

KRAS

Brain metastases

Bone metastases

Survival

\begin{abstract}
A B S T R A C T
Objectives: Both bone and brain are frequent sites of metastasis in non-small cell lung cancer (NSCLC). Conflicting data exist whether EGFR mutant $(+)$ patients are more prone to develop brain metastases or have a better outcome with brain metastases compared to EGFR/KRAS wildtype (WT) or KRAS+ patients. For bone metastases this has not been studied.

Methods: In this retrospective case-control study all EGFR+ (exons 19 and 21) patients diagnosed at two pathology departments were selected (2004/2008 to 2012). For every EGFR+ patient a consecutive KRAS+ and WT patient with metastatic NSCLC ( $M N S C L C)$ was identified. Patients with another malignancy within 2 years of mNSCLC diagnosis were excluded. Data regarding age, gender, performance score, histology, treatment, bone/brain metastases diagnosis, skeletal related events (SRE) and subsequent survival were collected.

Results: 189 patients were included: 62 EGFR+, 65 KRAS+, 62 WT. 32\%, 35\% and 40\%, respectively, had brain metastases $(p=0.645)$. Mean time to brain metastases was $20.8[ \pm 12.0], 10.8[ \pm 9.8], 16.4[ \pm 10.2]$ months (EGFR+-KRAS+, $p=0.020$, EGFR+-WT, $p=0.321$ ). Median post brain metastases survival was 12.1 [5.0-19.1], 7.6 [1.2-14.0], 10.7 [1.5-19.8] months $(p=0.674) .60 \%, 52 \%$ and 50\% had metastatic bone disease $(p=0.528)$. Mean time to development of metastatic bone disease was $13.4[ \pm 10.6], 23.3[ \pm 19.4]$, $16.4[ \pm 9.6]$ months $(p=0.201)$. Median post metastatic bone disease survival was 15.0 [10.6-20.3], 9.0 [5.2-12.9], 3.2 [0.0-6.9] months $(p=0.010)$. Time to 1 st SRE was not significantly different.

Conclusions: Incidence of brain and bone metastases was not different between EGFR+, KRAS+ and WT patients. Post brain metastases survival, time from mNSCLC diagnosis to metastatic bone disease and $1 \mathrm{st}$ SRE did not differ either. Post metastatic bone disease survival was significantly longer in EGFR+ patients. Although prevention of SRE's is important for all patients, the latter finding calls for a separate study for SRE preventing agents in EGFR+ patients.
\end{abstract}

(C) 2014 Elsevier Ireland Ltd. All rights reserved.

\footnotetext{
* Corresponding author. Tel.: +31 0433871318; fax: +31 0433875051.

E-mail address: lizza.hendriks@mumc.nl (L.E.L. Hendriks).
}

\section{Introduction}

Metastatic non-small cell lung cancer (mNSCLC) patients with activating epidermal growth factor receptor mutations (EGFR+) have, compared to KRAS mutated (KRAS+) or EGFR/KRAS wildtype (WT) patients, a longer progression free survival (PFS) and overall survival (OS) when treated with EGFR-tyrosine kinase inhibitors 
(TKI) [1-3]. Differences in tumor biology may also reflect metastatic pattern. Similar to patients with (EGFR/erB family member) HER2 positive breast cancer [4], the incidence of brain metastases may be higher in EGFR+ patients as compared to EGFR- patients[5-9]. One explanation is the inability of currently available EGFR-TKI to cross the intact blood-brain barrier at recommended doses [10]. In the above mentioned studies only patients with brain metastases were enrolled $[5,7,9]$ and/or mutation status was not known for all included patients $[6,8,9]$. Thus, the question whether the time to development of brain metastases and outcome is different between EGFR+, KRAS+ or WT patients could not be answered. Next to brain, bone is a frequent site of metastasis in NSCLC exerting a negative impact on quality of life [11-13]. Brain metastases have also a negative impact on survival [14]. Different metastatic patterns may have implications for diagnostic strategies (e.g. screening) and treatment decisions (e.g. prophylactic treatment).

In this retrospective case-control study we compared EGFR+ to KRAS+ and WT mNSCLC patients to determine whether EGFR+ patients are more prone to develop brain metastases and/or metastatic bone disease, and whether they have a different survival following the detection of these metastases.

\section{Materials and methods}

This study was designed as a retrospective case-control study, using a prospectively collected database.

Patient selection: All EGFR+ patients who were diagnosed at the pathology departments of two university hospitals (MUMC+ and VUMC) were selected. For every EGFR+ patient the consecutive KRAS+ and WT NSCLC patient was selected. The MUMC+ database covers the period 01-10-2008 to 01-08-2012 and the VUMC database 01-11-2004 to 01-01-2012. The MUMC+ pathology department performs mutation analysis for the MUMC+ (both general and referral hospital) and four surrounding general hospitals. From the VUMC database only patients who underwent treatment at VUMC (mainly referral hospital) were selected in order to obtain sufficient follow-up data.

Inclusion criteria: mNSCLC and known mutation status (activating EGFR+: exon 19 deletion or exon 21 mutation, KRAS+ or WT (defined as: no EGFR or KRAS mutation)).

Exclusion criteria: exon 18 or 20 EGFR mutation, other active malignancy within 2 years of diagnosis of mNSCLC, mixed histology, EML4-ALK translocation positive (when testing was performed) or no follow-up data available (at least one visit after diagnosis of mNSCLC required).

The in- and outpatient medical records of all patients were retrieved and the following data were collected: age at diagnosis of mNSCLC; gender; smoking status; date of first diagnosis NSCLC and of mNSCLC; histology; treatment; development, number, symptoms and treatment of brain metastases; development, and treatment of metastatic bone disease, skeletal related event (SRE) and time of death. Last date of follow-up was August 2013.

Medical ethical committee approval was not obtained in accordance with local regulations, as it is a retrospective study with no interventions.

\subsection{Mutation analysis}

Mutation analysis for EGFR (exons 18-21) and KRAS (exons 2-3) was performed as part of standard of care with high resolution melting as pre-screening followed by Sanger sequencing to confirm genotype [15].

\subsection{Statistical analysis}

Statistics were performed using SPSS (IBM statistics, version 20). Descriptive statistics of demographic and clinical variables were obtained. Categorical variables were compared using chisquare tests, continuous variables were compared using ANOVA. For patients without metastatic bone disease or brain metastases at first diagnosis of mNSCLC, time to diagnosis of these metastases was calculated from diagnosis of MNSCLC and was expressed as mean with standard deviation (SD). Means were compared using ANOVA with, if statistically significant, post hoc Student's $t$-tests for pair wise comparisons. OS was defined as time from diagnosis of mNSCLC to death and post metastatic bone disease and post brain metastases survival was calculated from diagnosis of these metastases to death (patients without event were censored at last visit). Both were estimated using the Kaplan-Meier method. Survival curves were compared using the log-rank test. To estimate the hazard ratio (HR), Cox regression analysis was used.

\section{Results}

\subsection{Patient characteristics}

Respectively 59/603 (9.8\%) and 26/346 (7.5\%) NSCLC patients included in the MUMC+ and VUMC database carried an EGFR mutation. These 85 EGFR+ patients were paired with the consecutive KRAS+ and WT patients. The medical records of these 255 patients were analyzed. 3 EGFR+ patients had an exon 18 mutation and 8 had an exon 20 mutation; these patients were excluded together with the consecutive KRAS+ and WT patient. In addition, 33 patients were excluded because of: no metastatic disease $(N=13)$, another malignancy diagnosed within 2 years of mNSCLC diagnosis $(N=10)$, no follow up data $(N=8)$ or ALK translocation $(N=2)$. Finally, 189 patients were included in the analysis: 62 EGFR+, 65 KRAS+ and 62 EGFR/KRAS WT (WT). Patient characteristics are shown in Table 1. Most EGFR+ patients (58/62 (93.5\%)) received an EGFR-TKI during the course of their disease, $41 / 58$ (70.7\%) as first line treatment.

Of the 62 EGFR+ patients, 41 had exon 19 deletions and 21 had exon 21 mutations (of which one combined with an exon 19 deletion).

\subsection{Overall survival}

Median OS [95\% CI] was significantly longer for EGFR+ patients compared to KRAS+ and WT patients: 26.7 [20.4-32.9]; 11.0 [6.8-15.1] and 11.5 [7.6-15.3] months respectively (HR 1.379 [1.135-1.677], $p<0.0001$, Fig. 1). Within the EGFR+ group, median OS was significantly longer for exon 19 than in exon 21 mutated

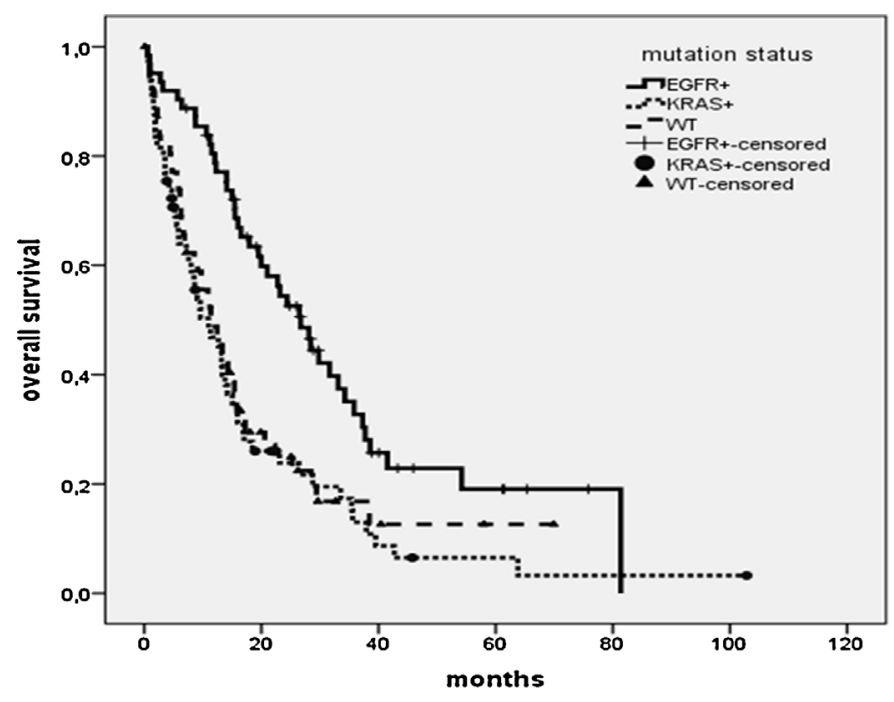

Fig. 1. Overall survival for EGFR+, KRAS+ arid WT patients. 
Table 1

Patient characteristics.

\begin{tabular}{|c|c|c|c|c|}
\hline Characteristics & $\begin{array}{l}\text { EGFR+ } \\
N=62\end{array}$ & $\begin{array}{l}\text { KRAS+ } \\
N=65\end{array}$ & $\begin{array}{l}\text { Wildtype } \\
N=62\end{array}$ & \\
\hline Female $N(\%)$ & $46(74.2)$ & $38(58.5)$ & $26(41.9)$ & 0.001 \\
\hline Mean age, years (range) & $60.7(29.3-90.7)$ & $61.0(35.1-83.3)$ & $63.0(39.6-81.8)$ & 0.532 \\
\hline Never smoker $N(\%)$ & $25(40.3)$ & $2(3.1)$ & $9(14.5)$ & $<0.001$ \\
\hline WHO PS 0-2 N(\%) & $59(95.2)$ & $62(95.4)$ & $60(96.8)$ & 0.164 \\
\hline Adenocarcinoma $N(\%)$ & $57(91.9)$ & $53(81.5)$ & $52(83.9)$ & 0.217 \\
\hline Stage IV disease at first diagnosis $N(\%)$ & $54(87.1)$ & $49(75.4)$ & $61(83.9)$ & 0.205 \\
\hline PET-CT at first diagnosis of metastatic disease $N(\%)^{\mathrm{a}}$ & $38(61.3)$ & $46(70.8)$ & $48(77.4)$ & 0.232 \\
\hline $\begin{array}{l}\text { Mutation analysis performed at first diagnosis of } \\
\text { metastatic disease } N(\%)\end{array}$ & $42(67.7)$ & $45(69.2)$ & $47(75.8)$ & 0.480 \\
\hline \multicolumn{5}{|l|}{ 1st line treatment $N(\%)$} \\
\hline None & $3(4.8)$ & $8(12.3)$ & $11(17.7)$ & 0.080 \\
\hline Chemotherapy & $18(29.0)$ & $55(84.6)$ & $46(74.2)$ & $<0.001$ \\
\hline EGFR-TKI & $41(66.2)$ & $2(3.1)$ & $5(8.1)$ & $<0.001$ \\
\hline EGFR-TKI during course of disease $N(\%)$ & $58(93.5)$ & $16(24.6)$ & $15(24.2)$ & $<0.001$ \\
\hline
\end{tabular}

EGFR, epidermal growth factor receptor; WHO PS, World Health Organisation Performance Score; TKI, tyrosine kinase inhibitor.

a Except for one wildtype patient and for four patients missing data: all other patients Ct-thorax/upper abdomen.

patients: 29.8 [22.1-37.5] and $15.5[9.4-22.6]$ months, respectively (HR $1.550[1.122-2.141], p=0.006)$.

\subsection{Brain metastases}

Incidence of brain metastases was not different between the 3 groups: 20/62 (32.3\%) EGFR+, 23/65 (35.4\%) KRAS+ and 25/62 $(40.3 \%)$ WT patients had brain metastases $(p=0.645)$. At diagnosis of mNSCLC brain metastases were present in 5/20 (25.0\%), 9/23 (39.1\%) and $13 / 25(52.0 \%)$ patients $(p=0.184)$. Mean time [SD] to diagnosis of brain metastases for patients without brain metastases at initial diagnosis of mNSCLC was 20.8 [ \pm 12.0$]$; $10.8[ \pm 9.8]$ and 16.4 [ \pm 10.2$]$ months, respectively. EGFR+ patients had a significantly longer time to development of brain metastases than KRAS+ $(p=0.020)$ but not compared to WT patients $(p=0.321)$. No significant difference in median $[95 \% \mathrm{CI}]$ post brain metastases survival was observed: 12.1 [5.0-19.1]; 7.6 [1.2-14.0] and 10.7 [1.5-19.8] months (HR 1.119 [0.801-1.565], $p=0.674$, Table 2, Fig. 2).

All 15 EGFR+ patients who developed brain metastases after initial diagnosis of mNSCLC were treated with an EGFR-TKI during the course of their disease (9/15 (60\%) first line, $12 / 15$ (80\%) before development of brain metastases). Mean time [SD] to development

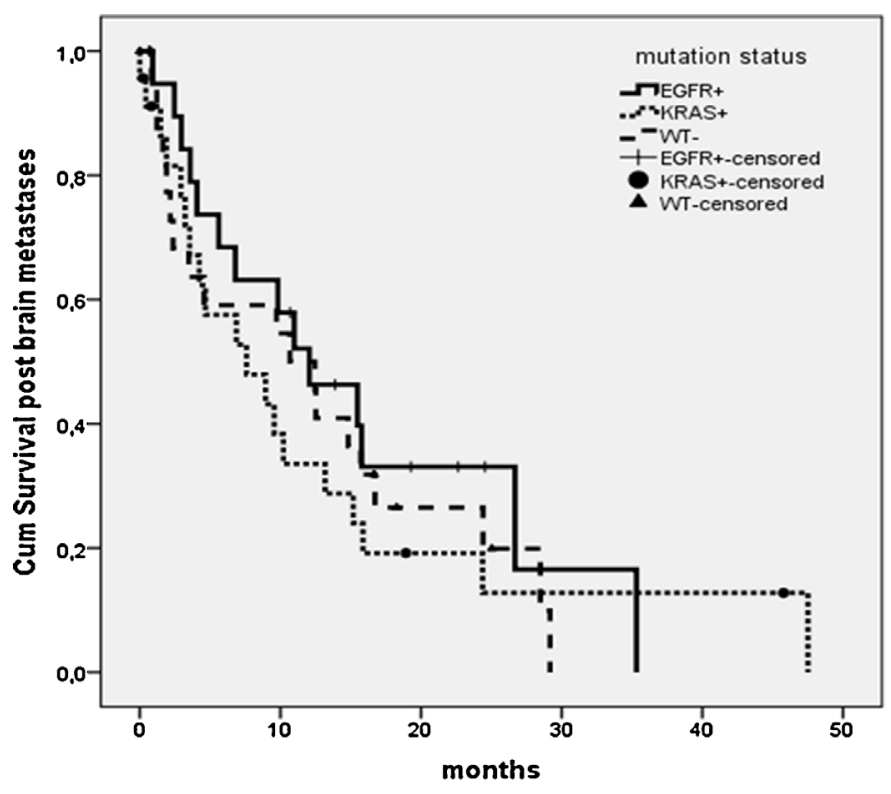

Fig. 2. survival post brain metastases for EGFR+, KRAS+ and WT patients. of brain metastases was not significantly different between EGFR+ patients who were in first line treated with an EGFR-TKI versus patients who received it in a later line $(21.3[ \pm 12.9]$ months versus $18.8[ \pm 9.2]$ months $p=0.760$ ) nor was there a significant difference in time to brain metastases for patients who received an EGFRTKI or only chemotherapy before development of brain metastases (21.4 $[ \pm 12.4]$ months versus $17.3[ \pm 12.5]$ months, $p=0.675)$. In the latter group $(N=3)$ EGFR-TKI treatment was started after diagnosis of brain metastases. Median survival $[95 \% \mathrm{CI}]$ post brain metastases was not significantly different between patients receiving an EGFRTKI before or after development of brain metastases (6.8 [0.0-18.9] months compared to 11.0 [9.1-12.8] months) ( $p=0.808)$. In addition no difference in OS was observed (37.3 [16.5-58.1] months and 31.6 [12.2-51.1] months, respectively, $p=0.861$ ).

\subsection{Metastatic bone disease}

Incidence of bone metastases was also not different between EGFR, KRAS+ and WT patients: 37/62 (59.7\%) EGFR+, 34/65 (52.3\%) KRAS+ and $31 / 62$ (50.0\%) WT patients were diagnosed with or developed metastatic bone disease during the course of their disease $(p=0.528)$. Of these 20/37 (54.1\%), 26/34 (76.5\%) and 18/31 $(58.1 \%)$, respectively, had metastatic bone disease at diagnosis of $\operatorname{mNSCLC}(p=0.121)$. Mean time [SD] to first diagnosis of metastatic bone disease for patients without metastatic bone disease at initial diagnosis of mNSCLC was respectively 13.4 [ \pm 10.6$] ; 23.3$ $[ \pm 19.4]$ and $16.4[ \pm 9.6]$ months for EGFR+, KRAS+ and WT patients, $(p=0.201)$. No difference in SRE's was observed: $19 / 37(51.4 \%)$, $22 / 34(64.7 \%)$ and $15 / 31(48.4 \%)$, respectively $(p=0.361)$. Also, time to first SRE was equal $(p=0.213)$. However, post metastatic bone disease survival was significantly longer in the EGFR+ group: median [95\% CI] of 15.5 [10.6-20.3] months compared to 9.0 [5.2-12.9] months for KRAS+ and 3.2 [0-6.9] months for WT patients. (EGFR+-KRAS+, $p=0.049$, EGFR+-WT, $p=0.004$ ), Table 2, Fig. 3). Mean time [SD] to development of metastatic bone disease was longer, however not significant, for EGFR+ patients first line treated with EGFR-TKI (15.9 $[ \pm 11.1]$ months) compared to those treated initially with chemotherapy $(7.3[ \pm 6.7]$ months $)(p=0.380)$.

\section{Discussion}

It is well known that patients presenting with an activating EGFR mutation have a better prognosis than KRAS+ or WT patients [1-3]. Although it is frequently suggested that EGFR+ patients, like HER2 positive breast cancer patients, are more prone to develop brain metastases during the course of their disease [5-9], this could not 
Table 2

Mutation status and bone/brain metastases.

\begin{tabular}{|c|c|c|c|c|}
\hline & $\begin{array}{l}\text { EGFR+ } \\
N=62\end{array}$ & $\begin{array}{l}\text { KRAS+ } \\
N=65\end{array}$ & $\begin{array}{l}\text { Wildtype } \\
N=62\end{array}$ & $p$-Value \\
\hline \multicolumn{5}{|l|}{ Brain metastases } \\
\hline \multicolumn{5}{|l|}{ Imaging at 1st diagnosis of mNSCLC N (\%) } \\
\hline MRI & $15(24.2)$ & $19(29.2)$ & $18(29.0)$ & 0.417 \\
\hline $\mathrm{CT}$ & $20(32.3)$ & $25(38.5)$ & $28(45.2)$ & \\
\hline None $^{c}$ & $25(40.3)$ & $19(29.2)$ & $16(25.8)$ & \\
\hline Missing & $2(3.2)$ & $2(3.1)$ & $0(0.0)$ & \\
\hline \multicolumn{5}{|l|}{ Brain mets $N(\%)$} \\
\hline Yes & $20(32.3)$ & $23(35.4)$ & $25(40.3)$ & 0.645 \\
\hline At diagnosis & $5(25.0)$ & $9(39.1)$ & $13(52.0)$ & 0.184 \\
\hline During follow up & $15(75.0)$ & $14(60.9)$ & $12(48.0)$ & \\
\hline No & $42(67.7)$ & $42(64.6)$ & $37(59.7)$ & \\
\hline Time to brain mets months [SD] & $20.8[ \pm 12.0]$ & $10.8[ \pm 9.8]$ & $16.4[ \pm 10.2]$ & $\begin{array}{l}\text { EGFR/KRAS } 0.020 \text {, } \\
\text { EGFR/WT } 0.321\end{array}$ \\
\hline EGFR-TKI before brain mets N (\%)- (first line) & $15(100.0)-12(80)$ & $1(7.1)$ & $4(33.3)$ & $<0.001$ \\
\hline Symptomatic $N(\%)$ & $16(80.0)$ & $17(73.9)$ & $24(96.0)$ & 0.097 \\
\hline WBRT $N(\%)$ & $12(60.0)$ & $11(47.8)$ & $20(80.0)$ & 0.028 \\
\hline SRS $N(\%)$ & $2(10.0)$ & $8(34.8)$ & $6(24.0)$ & 0.161 \\
\hline Surgery $N(\%)$ & $0(0.0)$ & $3(13.0)$ & $1(4.0)$ & 0.260 \\
\hline Post brain mets survival months [95\% CI] & $12.1[5.0-19.1]$ & $7.6[1.2-14.0]$ & $10.7[1.5-19.8]$ & 0.674 \\
\hline \multicolumn{5}{|l|}{ Bone metastases } \\
\hline \multicolumn{5}{|l|}{ Imaging at 1st diagnosis of mNSCLC N (\%) } \\
\hline PET-CT & $38(61.3)$ & $46(70.8)$ & $48(77.4)$ & 0.232 \\
\hline $\mathrm{CT}^{\mathrm{a}}$ & $17(27.4)$ & $13(20.0)$ & $11(17.7)$ & \\
\hline Bone scintigraphy ${ }^{\mathrm{b}}$ & $5(8.1)$ & $4(6.2)$ & $2(3.3)$ & \\
\hline Missing & $2(3.2)$ & $2(3.0)$ & $1(1.6)$ & \\
\hline \multicolumn{5}{|l|}{ Bone mets $N(\%)$} \\
\hline Yes & $37(59.7)$ & $34(52.3)$ & $31(50.0)$ & 0.528 \\
\hline At diagnosis & $20(54.1)$ & $26(76.5)$ & $18(58.1)$ & 0.121 \\
\hline During follow up & $17(45.9)$ & $8(23.5)$ & $13(41.9)$ & \\
\hline No & $25(40.3)$ & $31(47.7)$ & $31(50.0)$ & \\
\hline Time to bone mets months [SD] & $13.4[ \pm 10.6]$ & $23.3[ \pm 19.4]$ & $16.4[ \pm 9.6]$ & 0.201 \\
\hline $\mathrm{SRE}+N(\%)$ & $19(51.4)$ & $22(64.7)$ & $15(48.4)$ & 0.361 \\
\hline Time to 1 st SRE months $[95 \% \mathrm{CI}]$ & $12.9[5.0-20.7]$ & $7.3[0.0-14.9]$ & $3.5[0-7.7]$ & 0.213 \\
\hline Post bone mets survival months [95\% CI] & $15.5[10.6-20.3]$ & $9.0[5.2-12.9]$ & $3.2[0-6.9]$ & $\begin{array}{l}\text { EGFR/KRAS } 0.049 \\
\text { EGFR/WT } 0.004\end{array}$ \\
\hline
\end{tabular}

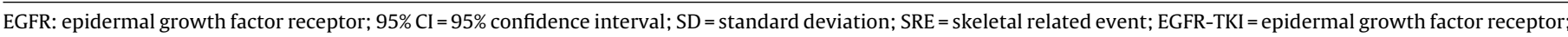
WBRT $=$ whole brain radiotherapy; SRS = stereotactic radiosurgery.

a Ct-thorax/upper abdomen.

b When both PET-CT and bone scintigraphy were performed, patients were scored for "PET-CT".

c Only low dose CT brain during PET-CT was scored as "none".

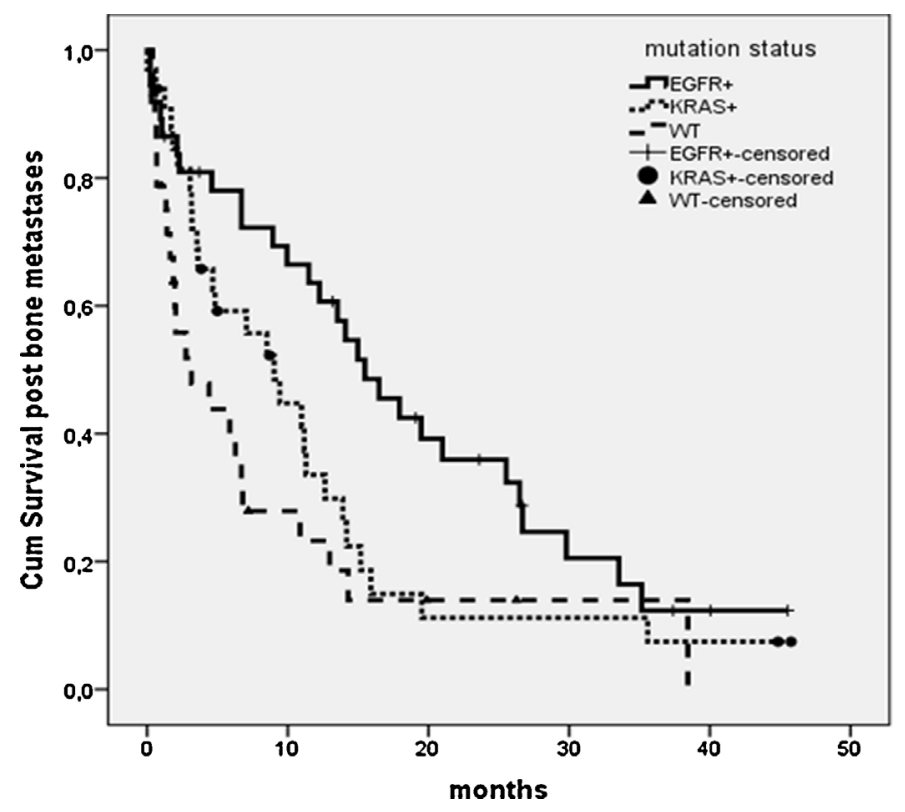

Fig. 3. Survival post bone metastases for EGFR+, KRAS+ and WT patients. be confirmed in our retrospective case-control study. To our knowledge, this is the first case control study of EGFR+, KRAS+ and WT patients with follow-up from first diagnosis of mNSCLC to evaluate incidence of brain and bone metastases and survival thereafter. Although this was a retrospective study, bias regarding staging and treatment has been minimized by not selecting exclusively patients with brain metastases at diagnosis, but including all consecutive patients with an activating EGFR mutation and comparing the pattern of metastasis with consecutive KRAS+ and EGFR/KRAS WT patients. In the literature, one study is available that investigated the prevalence of metastases at first diagnosis of mNSCLC however without follow-up data [16]. In this study (209 consecutive nonsquamous mNSCLC patients, 39 EGFR+, 49 KRAS+, 41 ALK+ and 80 triple negative) comparable results were obtained. The percentage of bone and brain metastases was not significantly different between EGFR+, KRAS+, ALK+ and triple negative patients at initial diagnosis of mNSCLC [4].

In our study time to development of brain metastases was significantly longer in EGFR+ patients compared to KRAS+ patients, but survival post brain metastases was not significantly different. Although different treatments (EGFR-TKI versus chemotherapy) might influence development of and survival after brain metastases in EGFR+ patients in our study time to development of brain metastases was not significantly different for EGFR+ patients treated with EGFR-TKI compared to chemotherapy. However, with only 15 EGFR+ patients developing brain metastases after initial 
diagnosis of mNSCLC, numbers are too small to draw firm conclusions. In contrast, in a retrospective study of Heon et al., including 155 EGFR+ patients, time to central nervous system progression was significantly longer in the EGFR-TKI than in the chemotherapy group (median of 56 versus 31.6 months) [17]. In this study CNS progression was defined not only as newly diagnosed brain metastases, but also as growth of pre-existing metastases. Brain metastases in EGFR+ patients respond to treatment with EGFR-TKIs $[5,10,18-22]$ and radiation therapy $[22,23]$, with median survival post brain metastases of $12-19$ months [5,9,20,22]. Little is known of post brain metastases survival in EGFR+ patients treated with EGFR-TKI who develop brain metastases. In two retrospective studies $(N Y=100$ and $N=155)$, median survival after diagnosis of brain metastases was 5.5 [24] and 5.9 months [17]. Although not significant, in our study survival after diagnosis of brain metastases was shorter when a patient was on EGFR-TKI treatment compared to starting EGFR-TKI treatment after diagnosis of brain metastases (6.8 vs 11.0 months).

More aggressive treatment of EGFR+ patients developing brain metastases while on EGFR-TKI treatment might prolong post brain metastases survival. For example, treatment with irreversible EGFR-TKIs or pulse therapy EGFR-TKI has been studied [25-27]. In a phase I trial with afatinib, a NSCLC patient developed brain metastases during treatment with afatinib $10 \mathrm{mg}$ once daily, but had a 10 month lasting intracranial response on afatinib $40 \mathrm{mg}$ once daily [27]. In another study, 6/9 patients with EGFR mutant lung cancer who developed brain metastases during treatment with regular doses of EGFR-TKI had a partial response to pulse therapy erlotinib (median of $1500 \mathrm{mg}$ weekly), another 2 had stable disease. Median time to central nervous system (CNS) progression was 2.8 months (range 0.8-14.5)[26]. Another option is radiotherapy and continuation of EGFR-TKI, especially when the brain is the only site of progressive disease $[28,29]$. In one study, CNS response rate and disease control rate were $41 \%$ and $76 \%$, respectively. Median OS was 408 days [28]. In another study, PFS was 1.7-11.1 months, OS was not mentioned [29].

Our study did also not show a different incidence and time to development of metastatic bone disease between EGFR+, KRAS+ and WT patients. Survival post metastatic bone disease was significantly longer in the EGFR+ group, but incidence of first SRE and time to first SRE was not different. Based on these results, it seems that EGFR+ patients have a longer survival with SREs. Prevention of metastatic bone disease and subsequent development of SREs (for example with bisphosphonates or denosumab) is important for all patients, but may be especially important in this subgroup of patients due to a longer survival with metastatic bone disease and the higher change of developing a SRE. This calls for a separate study of the effects of SRE preventing agents in EGFR+ patients. Strengths of the presented study include its multicenter character, the prospectively collected database and the case-control design. Limitations include its retrospective nature and the small number of patients with brain or bone metastases. As not all EGFR mutations confer the same sensitivity to TKIs, only patients with exons 19 and 21 mutations were included. Some patients only received best supportive care, but results did not change when we performed a subgroup analysis excluding these patients (data not shown). Finally, as current practice is not to screen for metastatic bone disease or brain metastases in mNSCLC, in our series patients did not undergo standard imaging at first diagnosis of metastasized disease or during follow-up, leading to a possible underdiagnosis of metastatic bone disease and brain metastases. Since the lack of brain and/or bone imaging at first diagnosis of mNSCLC was similar for the three groups, bias is less likely. To determine whether this influenced our data at first diagnosis of MNSCLC, we reanalyzed the data excluding patients who had no brain or bone imaging at first diagnosis of mNSCLC. Results were similar (data not shown).

\section{Conclusion}

Incidence of metastatic bone disease and brain metastases was not different between EGFR+, KRAS+ and WT patients. Furthermore, survival post metastatic bone disease was significantly longer in the EGFR+ group, which stresses the impact of bone management especially in these patients and probably warrant more intense screening for metastatic bone disease.

\section{Funding}

None.

\section{Conflict of interest statement}

The authors have declared no conflict of interest.

\section{References}

[1] Lynch TJ, Bell DW, Sordella R, Gurubhagavatula S, Okimoto RA, Brannigan BW, et al. Activating mutations in the epidermal growth factor receptor underlying responsiveness of non-small-cell lung cancer to gefitinib. N Engl J Med 2004;350:2129-39.

[2] Mok TS, Wu YL, Thongprasert S, Yang CH, Chu DT, Saijo N, et al. Gefitinib or carboplatin-paclitaxel in pulmonary adenocarcinoma. N Engl J Med 2009;361:947-57.

[3] Johnson ML, Sima CS, Chaft J, Paik PK, Pao W, Kris MG, et al. Association of KRAS and EGFR mutations with survival in patients with advanced lung adenocarcinomas. Cancer 2013;119:356-62.

[4] Lin NU, Winer EP. Brain metastases: the HER2 paradigm. Clin Cancer Res 2007; 13:1648-55.

[5] Eichler AF, Kahle KT, Wang DL, Joshi VA, Willers H, Engelman JA, et al. EGFR mutation status and survival after diagnosis of brain metastasis in nonsmall cell lung cancer. Neuro Oncol 2010;12:1193-9.

[6] Lee YJ, Choi HJ, Kim SK, Chang J, Moon JW, Park IK, et al. Frequent central nervous system failure after clinical benefit with epidermal growth factor receptor tyrosine kinase inhibitors in Korean patients with nonsmall-cell lung cancer. Cancer 2010;116:1336-43.

[7] Matsumoto S, Takahashi K, Iwakawa R, Matsuno Y, Nakanishi Y, Kohno T, et al. Frequent EGFR mutations in brain metastases of lung adenocarcinoma. Int $\mathrm{J}$ Cancer 2006;119:1491-4.

[8] Omuro AM, Kris MG, Miller VA, Franceschi E, Shah N, Milton DT, et al. High incidence of disease recurrence in the brain and leptomeninges in patients with nonsmall cell lung carcinoma after response to gefitinib. Cancer 2005;103:2344-8.

[9] Welsh JW, Komaki R, Amini A, Munsell MF, Unger W, Allen PK, et al. Phase II trial of erlotinib plus concurrent whole-brain radiation therapy for patients with brain metastases from non-small-cell lung cancer. J Clin Oncol 2013;31:895-902.

[10] Jamal-Hanjani M, Spicer J. Epidermal growth factor receptor tyrosine kinase inhibitors in the treatment of epidermal growth factor receptor-mutant nonsmall cell lung cancer metastatic to the brain. Clin Cancer Res 2012;18:938-44.

[11] Coleman RE. Metastatic bone disease: clinical features, pathophysiology and treatment strategies. Cancer Treat Rev 2001;27:165-76.

[12] Langer C, Hirsh V. Skeletal morbidity in lung cancer patients with bone metastases: demonstrating the need for early diagnosis and treatment with bisphosphonates. Lung Cancer 2010;67:4-11

[13] Langer CJ, Mehta MP. Current management of brain metastases, with a focus on systemic options. J Clin Oncol 2005;23:6207-19.

[14] Kepka L, Cieslak E, Bujko K, Fijuth J, Wierzchowski M. Results of the whole-brain radiotherapy for patients with brain metastases from lung cancer: the RTOG RPA intra-classes analysis. Acta Oncol 2005;44:389-98.

[15] Heideman DA, Thunnissen FB, Doeleman M, Kramer D, Verheul HM, Smit EF, et al. A panel of high resolution melting (HRM) technology-based assays with direct sequencing possibility for effective mutation screening of EGFR and K-ras genes. Cell Oncol 2009;31:329-33.

[16] Doebele RC, Lu X, Sumey C, Maxson DA, Weickhardt AJ, Oton AB, et al. Oncogene status predicts patterns of metastatic spread in treatment-naive nonsmall cell lung cancer. Cancer 2012;118:4502-11

[17] Heon S, Yeap BY, Lindeman NI, Joshi VA, Butaney M, Britt GJ, et al. The impact of initial gefitinib or erlotinib versus chemotherapy on central nervous system progression in advanced non-small cell lung cancer with EGFR mutations. Clin Cancer Res 2012;18:4406-14.

[18] Park SJ, Kim HT, Lee DH, Kim KP, Kim SW, Suh C, et al. Efficacy of epiderma growth factor receptor tyrosine kinase inhibitors for brain metastasis in nonsmall cell lung cancer patients harboring either exon 19 or 21 mutation. Lung Cancer 2012;77:556-60.

[19] Bai H, Han B. The effectiveness of erlotinib against brain metastases in nonsmall-cell lung cancer patients. Am J Clin Oncol 2012. 
[20] Porta R, Sanchez-Torres JM, Paz-Ares L, Massuti B, Reguart N, Mayo C, et al. Brain metastases from lung cancer responding to erlotinib: the importance of EGFR mutation. Eur Respir J 2011;37:624-31.

[21] Soffietti R, Trevisan E, Ruda R. Targeted therapy in brain metastasis. Curr Opin Oncol 2012;24:679-86.

[22] Hsiao SH, Lin HC, Chou YT, Lin SE, Kuo CC, Yu MC, et al. Impact of epidermal growth factor receptor mutations on intracranial treatment response and survival after brain metastases in lung adenocarcinoma patients. Lung Cancer 2013;81:455-61.

[23] Gow CH, Chien CR, Chang YL, Chiu YH, Kuo SH, Shih JY, et al. Radiotherapy in lung adenocarcinoma with brain metastases: effects of activating epidermal growth factor receptor mutations on clinical response. Clin Cancer Res 2008; 14 : $162-8$.

[24] Heon S, Yeap BY, Britt GJ, Costa DB, Rabin MS, Jackman DM, et al. Development of central nervous system metastases in patients with advanced non-small cell lung cancer and somatic EGFR mutations treated with gefitinib or erlotinib. Clin Cancer Res 2010;16:5873-82.
[25] Clarke JL, Pao W, Wu N, Miller VA, Lassman AB. High dose weekly erlotinib achieves therapeutic concentrations in CSF and is effective in leptomeningeal metastases from epidermal growth factor receptor mutant lung cancer. J Neurooncol 2010;99:283-6.

[26] Grommes C, Oxnard GR, Kris MG, Miller VA, Pao W, Holodny AI, et al. Pulsatile high-dose weekly erlotinib for CNS metastases from EGFR mutant non-small cell lung cancer. Neuro Oncol 2011;13:1364-9.

[27] Yap TA, Vidal L, Adam J, Stephens P, Spicer J, Shaw H, et al. Phase I trial of the irreversible EGFR and HER2 kinase inhibitor BIBW 2992 in patients with advanced solid tumors. J Clin Oncol 2010;28:3965-72.

[28] Shukuya T, Takahashi T, Naito T, Kaira R, Ono A, Nakamura Y, et al. Continuous EGFR-TKI administration following radiotherapy for non-small cell lung cancer patients with isolated CNS failure. Lung Cancer 2011;74:457-61.

[29] Weickhardt AJ, Scheier B, Burke JM, Gan G, Lu X, Bunn Jr PA, et al. Local ablative therapy of oligoprogressive disease prolongs disease control by tyrosine kinase inhibitors in oncogene-addicted non-small-cell lung cancer. J Thorac Oncol 2012;7:1807-14. 